\title{
Unaddressed issues in Janani Suraksha Yojana in India
}

\author{
Roy MP 1
}

${ }^{1}$ Assistant Professor, Department of Community Medicine, KPC Medical College and Hospital, Jadavpur,

Kolkata, West Bengal (India).

\section{Chief Editor}

Dr. Pradeep Aggarwal

\section{Technical Editor}

Dr. Nishida Chandrasekharan

Formatting Editor

Dr. Brijesh Sathian

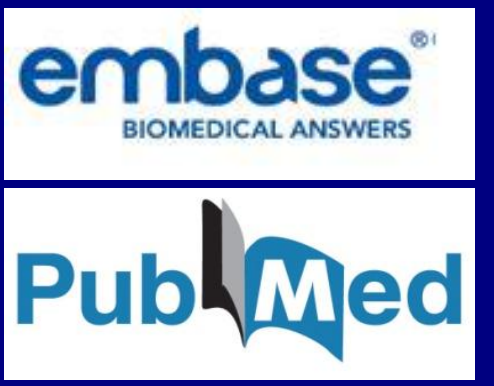

\section{Short Communication}

\author{
Corresponding Author: \\ Dr. Manas P Roy \\ Assistant Professor, Department of Community Medicine, \\ KPC Medical College and Hospital, Jadavpur, Kolkata, \\ West Bengal (India). \\ E-mail: proy.manas@gmail.com
}

\section{Abstract}

Janani Suraksha Yojana (JSY), a combination scheme of performance based financing and conditional cash transfer for safe motherhood, has increased ante natal coverage and institutional deliveries in India. Although the two concepts have been criticized world over for both positive and negative aspects; rarely the role of these two mechanisms behind the success of JSY has been addressed. Quality, costeffectiveness and other issues were never given due emphasis under this scheme neither efforts have been made to overcome known drawbacks of these strategies. Considering future of the scheme and sustainability, it is required to evaluate the concepts separately.

Keywords: Conditional cash transfer, Janani Suraksha Yojana, National Rural Health Mission, Performance based financing.

\section{Background}

India is the largest contributor in the global pool of maternal mortality. For addressing the challenge, National Rural Health Mission (NRHM), a new strategy was adopted in 2005. Under NRHM, Janani Suraksha Yojana (JSY) is a centrally sponsored scheme with cash assistance for institutional delivery (ID), particularly focused on socially and economically deprived population. ASHA (Accredited Social Health Activist), a group of rural health workers, were introduced as its baseline soldiers. While there is a provision for performance based financing (PBF) for these workers, there is also room for conditional cash transfer (CCT) for beneficiaries for getting ante natal care services as well as ID. The amount of incentive given to ASHA is not uniform across the country. Depending on health parameters, low performing states were given priority. Similarly, higher incentive is given in rural area than in urban locality. In some cases, state government has added some other components to the scheme to make it more attractive.

So far, many a studies have been devoted towards assessment of JSY and the scheme has been credited with success. With completion of seven years of scheme in 2012, it is probably high time to look back and find some issues of this scheme still unaddressed from Indian perspective.

\section{PBF in health care delivery}

Considering recent trend in health care delivery system in developing countries, PBF is one of the most discussed topics. Shortage of health care manpower along with suboptimal utilization of health care delivery services has given birth to this concept. After its success in Africa, it was adopted in India under JSY.

But rarely, if ever, the role of PBF under JSY was addressed. Most of the studies are concentrated on whether ASHA could bring some changes in the health care seeking attitude of the rural beneficiaries - ID, to be more precise. 
The fact that JSY is a mix of PBF and CCT is largely neglected among the researchers. The pregnant women are coming to health facilities mostly for their own economic benefits. Whether the same economic boost is motivating ASHA to encourage the beneficiaries to come to the health facilities are not clear yet.

First, let us interrogate the role of PBF in health care. Claimed to have boosted motivation and productivity of health care providers, PBF is still a controversial subject as it demands a balance between quality and quantity of the services provided. With diversion of a considerable fraction of health budget into the scheme, it is not inappropriate to raise question about its effectiveness; because in absence of strong monitoring, corruption and false reporting would have the capacity to spoil the party.

True, it allows the health facilities to be more selfdependent instead of centrally regulated health care system ${ }^{1}$. But, its effect in the long run is yet to be proved. Some opposed the idea that PBF could be used for health sector reform in developing countries ${ }^{2}$. Due to lack of evidence, a control group in particular, the improvements cannot always be attributed to $\mathrm{PBF}^{3}$.

One problem in India is that before NRHM, there was no concept of ASHA. The cadre was introduced with PBF. So, we simply cannot go for before-after comparison. This is difficult to assess the relative contribution of PBF in improvements of health parameters, given the influence of other ongoing changes in the program strategies (such as CCT, public private partnership) is largely unknown. The problem gets more complicated when we take state-wise variation into consideration. For example, Gujarat and Madhya Pradesh have modified the program with some other inputs.

JSY was seen to increase ante natal coverage as well as institutional deliveries, particularly in low performing states $^{4,5}$. It should be kept in mind that better documentation has sometimes seen to reflect improvement, without any underlying change in the real utilization $^{6}$. Even if we attribute the change to JSY, there is still no way that we could find out which component of JSY has brought in such success.

One way to assess the individual effect of PBF could be to see whether ASHA is successful in bringing out overall health related behaviors of villagers. All the aspects should be taken into consideration, starting from child care to completion of treatment under Revised National Tuberculosis Control Program (RNTCP), particularly at those services where CCT is not applied and not only institutional deliveries (ID).

Next, we seem to bother only about one variable i.e. the percentage of ID. Very rarely somebody seemed interested about the quality of services under JSY. A well familiar drawback regarding PBF is its ignorance about quality, given the focus fully centered on quantity, (or number of ID), although initially it was designed to meet the targets both in terms of quality and quantity ${ }^{2}$.

\section{CCT in health care}

CCT has been very much successful in Latin American countries like Brazil, Mexico and Nicaragua. Beneficiaries are offered cash assistance if they comply with a set of health behaviors. Distribution of cash is also believed to address the goal of poverty reduction. These programs have been seen to increase the utilization of health services but its effect on overall health status is not clear. A study found it to enhance growth, development and health of children in Mexico ${ }^{7,8}$. Our condition is very much similar to this. IDs have been increased but the reduction of maternal and neonatal mortality is not very impressive. A study suggests that JSY is successful in reducing peri-natal mortality but maternal mortality was not improved ${ }^{5}$. This type of evaluation should come up more in numbers with separate focus on PBF and CCT.

Another point is its cost-effectiveness. Enough evidence is yet to come that CCT is less expensive than scaling up coverage of health intervention ${ }^{9}$. Although such an effect is clear from the experience in USA, convincing data from low and middle income countries are yet to come ${ }^{10}$. In a country where people are not having sufficient access to primary health care,

Among other issues, the possibility that other health workers would be demoralized if ASHAs receive more financial incentives than those who are in established longterm services is need to be considered ${ }^{11}$. Sometimes, an unnecessary demand for the remunerated service is induced among the users. Buying output may give rise to a concept that every health related action deserves special incentive, thus distorting the basic idea. ${ }^{12}$ The possibility of false reporting for the sake of getting incentives (also known as gaming) has already been pointed as a matter of concern $^{11,12}$. Previous experience shows that for retaining eligibility, mothers sometimes keep the baby malnourished or continue to get pregnant, as a side-effect for $\mathrm{CCT}^{10}$. Accurate reporting system, thus, is a pre-requisite in this regard $^{13}$.

As success is blind, question has never been raised about the future of JSY - whether discontinuation of financial benefits would witness a drop of achievements made so far. Maintaining a group of temporary workers solely based on PBF might be possible, keeping the trend of appointing contractual staffs at every level of health care delivery services. But, is it possible to distribute financial incentives to the beneficiaries, given the fact that after a certain period, we would definitely hit the target of institutional deliveries, in terms of quantitative progress. What awaits us after that, if we discontinue the incentives then?

The limitation of CCT as a temporary solution has been emphasized earlier. For long-term and sustained change, we need to address the underlying issues that can modify the behaviour in a more permanent way ${ }^{11}$. The same is about PBF. Very little effort has been registered so far to cast light on success of PBF in JSY. Considering the fact that less than three years are left before we touch the deadline of 2015 for fulfilling Millennium Development Goals, it does not seem possible to realize the targets in maternal or child health. The effect of the program on remote parameters like MMR and IMR needs to be weighed, after controlling for all other confounders. 


\section{Conclusion}

This is fact that health care improvement is a complex issue, not mere interaction of few objective factors. The individual role played by PBF and CCT behind the apparent success of JSY need to be explored and the shortcomings are to be addressed accordingly. With the launch of Janani Shishu Suraksha Karyakram, an initiative to provide free and noexpense delivery to mothers and free treatment to sick newborn, a new effort for reducing out-of-pocket expenditure has been put forward. Further research should consider this initiative also for scrutinizing the relative contribution of different strategies in improving health seeking behavior and maternal health as well.

\section{Author's Contribution:}

MPR designed the study, collecting and compiling the data; and drafted the manuscript. Manuscript was revised by MPR.

\section{Conflict of interest:}

There is no conflict of interest among authors arising from the study.

\section{References}

1. Soeters R, Vroeg P. Why there is so much enthusiasm for performance-based financing, particularly in developing countries? Bull World Health Organ. 2011;89:700 http://dx.doi.org/10.2471/BLT.11.089987

PMid:21897494 PMCid:PMC3165985

2. Ireland M, Paul E, Dujardin B. Can performance-based financing be used to reform health systems in developing countries? Bull World Health Organ. 2011;89:695-698. http://dx.doi.org/10.2471/BLT.11.87379

PMid:21897491 PMCid:PMC3165979

3. Scheffler RM. Pay for Performance (P4P) Programs in Health Services: What is the Evidence? World Health Report (2010) Background Paper, No 31

4. Town R, Kane R, Johnson P, Butler $M$. Economic incentives and physicians' delivery of preventive care: a systematic review. Am J Prev Med. 2005;28:234-40. http://dx.doi.org/10.1016/j.amepre.2004.10.013

PMid:15710282

5. Govt. of India \& UNFPA. Concurrent assessment of Janani Suraksha Yojana (JSY) scheme in selected states of India, 2008. 2009.

6. Lim SS, Dandona L, Hoisington JA, James SL, Hogan MC, Gakidou E. India's Janani Suraksha Yojana, a conditional cash transfer programme to increase births in health facilities: An impact evaluation. Lancet. 2010;375:2009-23. http://dx.doi.org/10.1016/S0140-6736(10)60744-1

7. Lagarde M, Haines A, Palmer N. Conditional cash transfers for improving uptake of health interventions in low- and middle-income countries: a systematic review.
JAMA. 2007;298:1900-10.

http://dx.doi.org/10.1001/jama.298.16.1900 PMid:17954541

8. Fernald LCH, Gertler PJ, Neufeld LM. Role of cash in conditional cash transfer programmes for child health, growth, and development: an analysis of Mexico's Oportunidades. Lancet. 2008;371:828-37. http://dx.doi.org/10.1016/S0140-6736(08)60382-7

9. Shibuya K. Conditional cash transfer: a magic bullet for health? Lancet 2008;371:789-91.

http://dx.doi.org/10.1016/S0140-6736(08)60356-6

10. Giuffrida A, Torgerson DJ. Should we pay the patient? Review of financial incentives to enhance patient compliance. BMJ. 1997;315:703-7.

http://dx.doi.org/10.1136/bmj.315.7110.703

11. Oxman $A D$, Fretheim A. Can paying for results help to achieve the Millennium Development Goals? Overview of the effectiveness of results based financing. J Evid Based Med. 2009;2:70-83.

http://dx.doi.org/10.1111/j.1756-5391.2009.01020.x PMID:21348993.

12. Meessen B, Kashala JP, Musango L. Output-based payment to boost staff productivity in public health centres: contracting in Kabutare district, Rwanda. Bull World Health Organ. 2007;85:108-15.

http://dx.doi.org/10.2471/BLT.06.032110

PMid:17308731 PMCid:PMC2636284

13. Eldridge $C$, Palmer N. Performance-based payment: some reflections on the discourse, evidence and unanswered questions. Health Policy Plan. 2009;24:160. http://dx.doi.org/10.1093/heapol/czp002

PMID:19202163

Article Information

Article history

Received $10^{\text {th }}$ March 2012

Received in revised form $12^{\text {th }}$ March 2014

Accepted $20^{\text {th }}$ March 2014 